\title{
Evaluating Quality Attributes of Four Fresh Fig (Ficus carica L.) Cultivars Harvested at Two Maturity Stages
}

\author{
Carlos H. Crisosto ${ }^{1}$, Vanessa Bremer, Louise Ferguson, \\ and Gayle M. Crisosto \\ University of California, Davis, Department of Plant Sciences, Mail Stop 2, \\ One Shields Avenue, Davis, CA 95616
}

Additional index words. "in-store" consumer test, DPPH analysis, demographics, cultivargenotype selection, firmness

\begin{abstract}
The effect of two fruit maturity stages on the quality attributes of four fresh fig cultivars was examined, including consumer acceptance and antioxidant capacity. Fig quality attributes such as weight, soluble solids concentration (SSC), titratable acidity (TA), SSC:TA, firmness, antioxidant capacity, and consumer acceptance varied by cultivar. Fig cultivars harvested at the advanced maturity stage ("tree ripe") had lower TA and firmness but higher weight, SSC, and SSC:TA than figs harvested at "commercial maturity." Fig maturity did not affect antioxidant capacity, but tree ripe figs had higher consumer acceptance than commercial maturity figs. SSC was more highly correlated with consumer acceptance than TA or SSC:TA, but other factors may also be important in controlling this relationship. Cultivars with high SSC and firmness, at a maturity stage high enough to tolerate harvesting and postharvest handling, should be selected to develop the fresh fig industry. Because fig firmness is a concern, changes to packaging should be evaluated to protect the flavor of advanced maturity figs during postharvest handling.
\end{abstract}

California fresh fig production has increased recently. As a result, there is now a market for cultivars with favorable fresh fig quality parameters and high consumer acceptance. Recent research demonstrated fig genotype and maturity stage influence fruit quality. Figs (Ficus carica L.) are a nutritious fruit rich in fiber, potassium, calcium, and iron (Chessa, 1997) with higher levels than other common fruits such as bananas, grapes, oranges, strawberries, and apples (Chessa, 1997; Michailides, 2003). Figs are free of sodium, fat-free, and, like other fruits, cholesterolfree. Additionally, figs are an important source of vitamins, amino acids, and antioxidants (Solomon et al., 2006). Compounds with antioxidant properties such as vitamin $\mathrm{C}$, tocopherols, carotenoids, and phenolics can alter the metabolic activation and detoxification/ disposition of carcinogens, affect processes that modify the development of tumor cells (Kader, 2001), and avoid neurochemical and behavioral changes related with aging (Shukitt-Hale et al., 2007). In addition, fruits and vegetables rich in phenolics have been shown to decrease cardio- and cerebrovascular diseases and cancer death rates (Hertog et al., 1997). Fig varieties with dark skin contain higher levels of polyphenols, anthocyanins, and flavonoids accompanied by higher antioxidant activity compared with fig varieties with lighter skin (Solomon et al., 2006).

Received for publication 9 Dec. 2009. Accepted for publication 25 Feb. 2010

${ }^{1}$ To whom reprint requests should be addressed; e-mail chcrisosto@ucdavis.edu.
Fig trees $(F$. carica L.) are among the earliest cultivated fruit trees in the world (Solomon et al., 2006). Although its origin is not entirely known, $F$. carica is thought to have originated in western Asia and from there slowly spread through the Mediterranean region (Stover et al., 2007b). Figs were brought to America in 1520 by the Spaniards, and in 1769 , they were introduced to California from Mexico. Figs are harvested worldwide on 419,000 ha with an annual production of over 1 million tons. The United States ranks sixth in the world's production, representing $4.6 \%$ of the total production (Food and Agriculture Organization, 2007). There are 5100 ha of figs in California, mainly in the San Joaquin Valley with yields triple the world's average yield. The main California cultivars are Calimyrna, Adriatic, Mission, Brown Turkey, and Kadota (Stover et al., 2007a). Until recently, fresh figs represented less than $5 \%$ of total fig production (Stover et al., 2007a); most of the California figs are destined for the dried market (Obenauf et al., 1978; Soby, 1997; Stover et al., 2007a; Tous and Ferguson, 1996). However, during the period from 2002 to 2006 , fresh fig production increased fourfold, constituting 16\% of California's 2006 fig production (U.S. Department of Agriculture, 2007). This increase in fresh fig production is a consequence of increasing consumer demand for fresh quality produce of less familiar fruits (Stover et al., 2007a). In a preliminary survey of 1200 men and women conducted by Synovate, only $67 \%$ of the people surveyed were familiar with figs and only $55 \%$ with fresh figs. Of those surveyed, only $39 \%$ had ever eaten fresh figs, whereas $77 \%$ had eaten figs in cookies or bars
(Synovate, 2004). The large number of consumers unaware of figs, combined with positive consumer perception, indicates there is potential for development of a fresh fig market. However, most current California fig cultivars were selected for drying, and the growers have little fresh fruit handling experience. If a profitable fresh fig industry is to be developed in California, cultivar selection, fruit maturity, and postharvest technology during marketing should be evaluated to produce the quality fresh fig that will increase consumer consumption. Therefore, this work investigated the impact of two fruit maturity stages on fresh fig quality attributes of four cultivars currently grown in California, including consumer acceptance.

\section{Materials and Methods}

Plant materials. Figs for this experiment were harvested from 8-year-old trees grown in a commercial fig orchard in Madera County, $\mathrm{CA}$, with a tree spacing of $3.7 \mathrm{~m} \times 7.3 \mathrm{~m}$. Four fresh fig cultivars (Mission, Brown Turkey, Calimyrna, and Kadota) were harvested at two maturity stages, commercial and tree ripe, in 2006. The California fig industry is largely based on these four cultivars and 'Adriatic' (Stover et al., 2007b). Figs were considered commercially mature when the fruit flesh gave slightly when touched, whereas tree ripe fruit was riper and softer than commercial maturity but not overripe. In general, tree ripe green and dark skin-colored fig cultivars were visually greener and darker than those harvested at commercial maturity. A few of the tree ripe fruit well exposed in the canopy had leakage from the ostiole.

Fruit selection and preparation. Seventyfive fig fruits per cultivar and maturity stage were used from each of the four replicated fig trees randomly selected in the field. Each fig cultivar and maturity stage was evaluated for initial quality attributes (after harvest) and consumer acceptance. Consumer acceptance was evaluated using an "in-store" consumer test as described subsequently (Crisosto and Crisosto, 2001)

Quality evaluations. Initial fruit quality attribute measurements included fresh weight, firmness, skin color, soluble solids concentration (SSC), titratable acidity (TA), ethylene production (evolved ethylene), respiration $\left(\mathrm{CO}_{2}\right.$ production), and antioxidant capacity. Individual fresh weight, firmness, and skin color (L, C, H) were measured on 15 fruit per cultivar and maturity. Individual fresh weight was measured with a digital scale (Model PM 4000; Mettler Instrument Corp., Hightstown, NJ) and expressed in grams. Fruit firmness was measured using a fruit texture analyzer (GS.14; Güss, Strand, South Africa) adapted with a flat tip. Each fig was compressed on the cheek with a $2.5-\mathrm{cm}$ flat tip at a speed of $5 \mathrm{~mm} \cdot \mathrm{s}^{-1}$ to a depth of $4 \mathrm{~mm}$ and the maximum value of force was expressed in Newtons $(\mathrm{N})$. Skin color was measured using a Minolta colorimeter (Model CR-200; Osaka, Japan). The data were expressed as luminosity $[\mathrm{L}$, ranging from darkness (negative L) to 
lightness (positive $\mathrm{L})]$, chroma $(\mathrm{C}$, indicating intensity or saturation of the color), and hue $[\mathrm{H}$, angle that indicates the pure spectrum color (i.e., which wavelength is most dominant)]. For SSC and TA, the flesh of five figs was pressed through cheesecloth with a hand press to obtain a composite juice sample (Crisosto et al., 2004). Four composite juice samples were obtained for each cultivar and maturity. The juice was used for determination of SSC with a temperature-compensated handheld refractometer (Model ATC-1; Atago Co., Tokyo, Japan) and the values were expressed as percentages. Three grams of each composite juice sample were used for determination of TA with an automatic titrator (Model 950; Orion, Boston, MA) and reported as a percentage of citric acid. For determination of ethylene production and respiration at $20{ }^{\circ} \mathrm{C}$, four fruit per cultivar and maturity were weighed individually with a digital scale and placed individually in $705-\mathrm{mL}$ sealed plastic containers. Air samples from the containers were withdrawn after $1 \mathrm{~h}$. The concentration of ethylene was determined with a gas chromatograph equipped with a flame ionization detector (Carle AGC-211; EG\&G Chandler Engineering, Tulsa, $\mathrm{OK}$ ), $8 \% \mathrm{NaCl}$ on Alumina F-1 column, helium $(275.7 \mathrm{kPa}, 30$ $\left.\mathrm{mL} \cdot \mathrm{min}^{-1}\right)$ as a carrier, and air and hydrogen (124.1 and $179.2 \mathrm{kPa}$, respectively) as combustion gases. Ethylene production rates were calculated and expressed as $\mu \mathrm{L} \mathrm{C}_{2} \mathrm{H}_{4} \cdot \mathrm{kg}^{-1} \cdot \mathrm{h}^{-1}$. The respiration rate was determined with an infrared $\mathrm{CO}_{2}$ analyzer (Model PIR-2000R; Horiba Instruments, Irvine, $\mathrm{CA}$ ) and calculated and expressed as $\mathrm{mL} \mathrm{CO} \cdot \mathrm{kg}^{-1} \cdot \mathrm{h}^{-1}$.

Antioxidant activity. Three replicates of $4 \mathrm{~g}$ of fig sample per cultivar and maturity stage were used to measure the levels of antioxidant capacity by the DPPH free radical method (Brand-Williams et al., 1995). Samples were extracted in methanol [highperformance liquid chromatography (HPLC) grade, EMD, MX0475P-1] and homogenized using a polytron (Ultra-Turrax TP 18/101 S1; Junke \& Kunkel, Staufen, Germany) for $40 \mathrm{~s}$. The homogenate was allowed to stand for $24 \mathrm{~h}$ at $4{ }^{\circ} \mathrm{C}$ in dark conditions and then centrifuged (Sorvall RC5C; Du Pont Company, Wilmington, DE) for $15 \mathrm{~min}$ at $14,000 \mathrm{rpm}$ at $4{ }^{\circ} \mathrm{C}$. The supernatant was collected and stored in dark conditions at $-80{ }^{\circ} \mathrm{C}$ until analysis. Antioxidant capacity was determined using a spectrophotometer (Thermomax Microplate Reader; Molecular Devices, Sunnyvale, CA). Into each well of a 96-well microtiter plate, $247 \mu \mathrm{L}$ DPPH (2,2-diphenyl-1-picrylhydrazyl, free radical) solution (121.7 mM in HPLCgrade methanol) was pipetted along with 13 $\mu \mathrm{L}$ of pure methanol (control), Trolox (watersoluble vitamin $\mathrm{E}$ analog) standard solution ( 88 to $800 \mu \mathrm{M}$; Cayman Chemical, Ann Arbor, $\mathrm{MI}$ ), or sample extract. After $24 \mathrm{~h}$ at $25^{\circ} \mathrm{C}$, absorbance was measured at $515 \mathrm{~nm}$ using methanol as a blank. The antioxidant capacity was expressed in micromoles Trolox equivalents per gram of fresh weight tissue ( $\mu \mathrm{mol} \mathrm{TE} /$ $\mathrm{g}$ FW).

"In-store" consumer test. For consumer acceptance evaluation, figs were stored after harvest at $0{ }^{\circ} \mathrm{C}$ for $1 \mathrm{~d}$ until the day of the consumer test. An "in-store" consumer test was conducted on the two maturity stages of the four fresh fig cultivars according to previous work (Crisosto and Crisosto, 2001). One hundred consumers, including a diverse combination of ages and genders, were surveyed at Whole Foods Market, Fresno, CA, in Aug. 2006.

Each consumer was presented, monadically, with eight fresh fig samples (one sample from each cultivar and maturity stage) in random order at room temperature $\left(20^{\circ} \mathrm{C}\right)$. A sample consisted of half of a fig cut longitudinally from the stem end to the ostiole end, and it was presented in a $163-\mathrm{mL}$ soufflé cup labeled with a three-digit code. The samples were prepared at the supermarket in the produce room out of sight from the testing area. Before tasting the samples, the consumers were asked about any possible allergic reactions to figs and how frequently they eat fresh figs; in addition, demographic data (gender, race, age range) were recorded. For each sample, the consumers were asked to taste it and then asked to indicate, all things considered, which statement best describes how they feel about the sample on a 9-point hedonic scale $(1=$ dislike extremely to $9=$ like extremely). The consumers were instructed to sip bottled water in between samples to cleanse their palate. Consumer acceptance was measured as both degree of liking (1 to 9 ) and percentage of acceptance. Percentage of acceptance was calculated as the number of consumers liking the sample (score greater than 5.0) divided by the total number of consumers within that sample (Lawless and Heymann, 1998). In a similar manner, the percentage of consumers disliking (score less than 5.0) and neither liking nor disliking (score $=5.0$ ) the sample were calculated.

Statistical analysis. The data from the fig initial quality (except antioxidant capacity) are presented using descriptive statistics as means and SDs by cultivar and maturity stage. Linear regressions were performed between quality and consumer acceptance parameters, and adjusted $R^{2}$ is reported for all significant regressions $(P \leq 0.05)$. The experimental design of antioxidant capacity was a $4 \times 2$ factorial design. The experimental design of the consumer test was repeated measures. The data from the consumer test were analyzed considering cultivar and maturity separately (two variables) as well as the combination cultivar-maturity (only one variable). The data from antioxidant capacity and the consumer test were analyzed using a general linear model with cultivar and maturity as fixed factors with the program SPSS (SPSS_16.0, 2008) and significance was tested at $P \leq 0.05$. Mean separation was determined by Tukey's honestly significant difference $(P \leq 0.05)$.

\section{Results and Discussion}

Quality evaluations. Fig weight, firmness, skin color, SSC, TA, and SSC:TA were all affected by cultivar, maturity stage, and by the interaction between these two factors. Therefore, only the interaction data are discussed (Table 1). Ethylene production was affected only by cultivar or maturity stage (data not shown). Furthermore, the respiration rate (47 to $67 \mathrm{~mL} \mathrm{CO} \mathrm{CO}_{2} \cdot \mathrm{kg}^{-1} \cdot \mathrm{h}^{-1}$ ) was unaffected by cultivar, maturity stage, or their interaction. Ethylene production was the highest in 'Mission' $\left(5.8 \mu \mathrm{L} \cdot \mathrm{kg}^{-1} \cdot \mathrm{h}^{-1}\right)$ and 'Brown Turkey' $\left(5.9 \mu \mathrm{L} \cdot \mathrm{kg}^{-1} \cdot \mathrm{h}^{-1}\right)$ followed by 'Kadota' (4.8 $\left.\mu \mathrm{L} \cdot \mathrm{kg}^{-1} \cdot \mathrm{h}^{-1}\right)$ and 'Calimyrna' $\left(4.12 \mu \mathrm{L} \cdot \mathrm{kg}^{-1} \cdot \mathrm{h}^{-1}\right)$ with the lowest. Ethylene production was lower at the tree ripe stage $\left(4.7 \mu \mathrm{L} \cdot \mathrm{kg}^{-1} \cdot \mathrm{h}^{-1}\right)$ than at the commercial stage $\left(5.7 \mu \mathrm{L} \cdot \mathrm{kg}^{-1} \cdot \mathrm{h}^{-1}\right)$. This decrease in ethylene production from commercial maturity to tree ripe maturity is consistent with observations that the climacteric peak in figs routinely occurs before commercial maturity, perhaps reflecting that the individual fruitlets in the composite fig synconium are physiologically mature before the softening of the fig (C.H. Crisosto, unpublished data). Skin color

Table 1. Interaction between cultivar and maturity stage on quality attributes of four fresh fig cultivars harvested from a commercial orchard in Madera County, CA, 2006.

\begin{tabular}{|c|c|c|c|c|c|c|c|c|c|}
\hline \multirow[b]{2}{*}{ Cultivar } & \multirow[b]{2}{*}{ Maturity stage } & \multirow[b]{2}{*}{ Wt (g) } & \multirow[b]{2}{*}{ FTA $(\mathrm{N})$} & \multicolumn{3}{|c|}{ Color $^{z}$} & \multirow[b]{2}{*}{$\operatorname{SSC}(\%)$} & \multirow[b]{2}{*}{ TA ( $\%$ citric acid $)$} & \multirow[b]{2}{*}{$\mathrm{SSC}: \mathrm{TA}$} \\
\hline & & & & $\mathrm{L}^{*}$ & Chroma & $\mathrm{Hue}^{\circ}$ & & & \\
\hline \multirow[t]{2}{*}{ Mission } & Commercial & 37.5 & 1.24 & 34.13 & 10.30 & 165.97 & 15.9 & 0.44 & 38.1 \\
\hline & Tree ripe & 35.6 & 0.85 & 30.86 & 4.03 & 271.21 & 19.1 & 0.38 & 51.0 \\
\hline \multirow[t]{2}{*}{ Brown Turkey } & Commercial & 44.3 & 1.07 & 37.04 & 18.75 & 30.12 & 15.9 & 0.28 & 56.9 \\
\hline & Tree ripe & 52.2 & 0.65 & 31.23 & 11.71 & 71.24 & 18.0 & 0.29 & 62.4 \\
\hline \multirow[t]{2}{*}{ Calimyrna } & Commercial & 52.7 & 2.29 & 69.95 & 54.31 & 112.00 & 15.7 & 0.62 & 25.8 \\
\hline & Tree ripe & 55.6 & 1.19 & 76.28 & 61.35 & 101.33 & 18.9 & 0.42 & 46.5 \\
\hline \multirow[t]{2}{*}{ Kadota } & Commercial & 49.5 & 1.55 & 68.86 & 50.65 & 112.75 & 18.6 & 0.65 & 28.5 \\
\hline & Tree ripe & 54.9 & 1.04 & 74.86 & 53.12 & 105.54 & 19.3 & 0.22 & 86.1 \\
\hline$P$ value & & $<0.0001$ & $<0.0001$ & $<0.0001$ & $<0.0001$ & $<0.0001$ & 0.0009 & $<0.0001$ & $<0.0001$ \\
\hline $\mathrm{LSD}_{0.05}$ & & 4.9 & 0.26 & 2.47 & 3.18 & 61.81 & 1.8 & 0.12 & 14.7 \\
\hline
\end{tabular}

${ }^{\mathrm{z}} \mathrm{L}^{*}, \mathrm{Chroma}$, and $\mathrm{Hue}^{\circ}$ are color parameters: lightness/darkness, chroma, and hue angle, respectively.

FTA = fruit texture analyzer; SSC = soluble solids concentration; TA = titratable acidity; LSD $=$ least significant difference. 
varied within each cultivar from green to yellow ('Calimyrna', 'Kadota') and brown to dark color ('Brown Turkey', 'Mission') as expected. Brown and black skin color cultivars turned darker and green-yellow skin color cultivars became more yellow at the higher maturity stage (tree ripe). Skin color expressed as luminosity and chroma were $\approx 30.86$ and 4.03 for the dark 'Mission' tree ripe and $\approx 76.28$ and 61.35 for the green 'Calimyrna' tree ripe, respectively. The higher values of luminosity and chroma of the green cultivars denote lighter and more intense colors. Hue values were $\approx 103^{\circ}$ for the green tree ripe cultivars, which is in the range of the green-yellow colors, $271.21^{\circ}$ for tree ripe 'Mission', in the range of blue colors, and $71.24^{\circ}$ for 'Brown Turkey', in the range of red-yellow colors.

'Mission' harvested at both maturity stages had the lowest weight $(\approx 36.5 \mathrm{~g})$ followed by 'Brown Turkey' harvested at commercial maturity. Fruit weight was higher for the other cultivar-maturity combinations and there was no significant difference among them (Table 1). The cultivar-maturity stage combinations were segregated into five groups according to their firmness. 'Calimyrna', a Smyrna type, had the highest firmness $(2.29 \mathrm{~N})$ when harvested at the commercial stage, and 'Brown Turkey', a common fig type, the lowest $(0.65 \mathrm{~N})$ when harvested at the tree ripe stage. Among the rest of the cultivar-maturity combinations, firmness ranged from 0.85 to $1.55 \mathrm{~N}$. Commercial 'Mission', tree ripe 'Calimyrna', and commercial 'Kadota' were firmer than tree ripe 'Brown Turkey' and 'Mission'. SSC was higher in tree ripe 'Mission', 'Brown Turkey', 'Calimyrna', and 'Kadota than the rest of the combinations. Commercial 'Mission', 'Brown Turkey', and 'Calimyrna' combinations had the lowest SSC. 'Brown Turkey' (both maturities) and tree ripe 'Kadota' had the lowest TA $(\approx 0.25 \%)$ followed by 'Mission' (both maturities) and tree ripe 'Calimyrna', whereas commercial 'Kadota' and 'Calimyrna' had the highest acidity $(0.62 \%)$. Therefore, tree ripe 'Kadota' had the highest SSC:TA followed by 'Brown Turkey' (both maturities) and tree ripe 'Mission'. The lowest SSC:TA was measured on 'Calimyrna' (both maturities) and commercial 'Kadota' and 'Mission'.

A similar range of SSC in fresh fig has been reported in these cultivars in Italy (Chessa, 1997), in Turkey (Aksoy, 1998; Aksoy et al., 2003; Ilgin and Küden, 1997; Küden et al., 2008), and for fig cultivars from different areas of the world that are growing in California (Bremer, 2008).

Antioxidant activity. Antioxidant capacity differed significantly between cultivars but not between maturity stages and there was no significant interaction between cultivars and maturity stages (Table 2). 'Mission' had the highest antioxidant capacity $(3.14 \mu \mathrm{mol} \mathrm{TE} / \mathrm{g}$ FW) followed by 'Calimyrna' and 'Brown Turkey' ( $\approx 1.80 \mu \mathrm{mol} \mathrm{TE} / \mathrm{g} \mathrm{FW})$, whereas 'Kadota' had the lowest antioxidant capacity (1.44 $\mu \mathrm{mol} \mathrm{TE} / \mathrm{g} \mathrm{FW})$. The higher antioxidant capacity of 'Mission', which was almost double the others, is likely attributed to its dark skin color. Our fig antioxidant capacity values were similar to the ones reported for cultivars and a selection of strawberries (Battino and Mezzetti, 2006), higher than the ones recently reported for peaches and plums (Wang et al., 2008), and equal to or lower than some reported for blueberry cultivars (Bremer et al., 2008). Similar results were observed in six commercial fig cultivars with different skin colors ('Brown Turkey', 'Brunswick', 'Bursa', 'Chechick', 'Kadota', and 'Mission') growing commercially under Israeli conditions (Solomon et al., 2006). Influence of genotype on antioxidant capacity has been reported in strawberries, apples, peaches, blueberries, and apricots (Bremer et al., 2008; Scalzo et al., 2005; Vizzotto et al., 2007).

In this study, it was observed that most of the compounds with antioxidant activity such as polyphenols, anthocyanins, and flavonoids were located in the fig skin. Thus, fig cultivars with dark skin contained higher levels of antioxidant activity compared with fig cultivars with lighter skin (Solomon et al., 2006). Polyphenols analysis carried out by HPLC confirmed that phenolics were mainly concentrated in the peel with black cultivars having the highest content (Piga et al., 2008). In vitro and in vivo studies have demonstrated that fig antioxidants were able to affect processes that alter the development of tumor cells and to avoid neurochemical and behavioral changes related with aging (Shukitt-Hale et al., 2007; Vinson et al., 2005).

The lack of significant differences in antioxidant capacity between maturity stages has been previously reported on peaches and plums. In dark color cultivars Brown Turkey and Mission, skin color turned dark during ripening demonstrated by hue angle measurements. This change in hue angle indicated that anthocyanins may have increased in figs harvested at the "tree ripe" stage; however, this suggested that the anthocyanin increase did not affect antioxidant capacity. In other species, it has been reported that antioxidant capacity was well correlated with the phenolics content but not with the anthocyanin content (Ferreyra et al., 2007).

"In-store" consumer test. The "in-store" consumer test population $(\mathrm{n}=100)$ consisted of $70.1 \%$ female and $29.4 \%$ male participants. Seventy percent of the consumer population was in the age range between 18 and 59 years old and $30 \%$ were 60 years old or older. The consumer population was formed by $78.3 \%$ Caucasians, $11.7 \%$ Hispanics, $3.6 \%$ Asians, $1.8 \%$ African Americans, and $4.6 \%$ others. Acceptance of the fresh fig cultivars tested was not significantly different between demographic subgroups in this population (data not shown).

The degree of liking of the four fresh fig cultivars evaluated in the "in-store" consumer test was affected by cultivar and maturity stage at harvest, but there was no significant interaction between cultivar and maturity stage (Table 3). Consumers liked 'Kadota' and 'Mission' moderately with an acceptance of $82 \%$ and $72 \%$, respectively. 'Calimyrna' and 'Brown Turkey' were liked slightly with
Table 2. Antioxidant capacity of four fresh fig cultivars $(n=3)$ harvested at commercial and tree ripe maturity stages from a commercial orchard in Madera County, CA, 2006.

TEAC $(\mu \mathrm{mol} \mathrm{TE} / \mathrm{g} \mathrm{FW})$

\begin{tabular}{ll}
\hline Cultivar $^{z}$ & \\
Mission & $3.14 \mathrm{a}$ \\
Brown Turkey & $1.73 \mathrm{bc}$ \\
Calimyrna & $1.88 \mathrm{~b}$ \\
Kadota & $1.44 \mathrm{c}$ \\
Significance & 0.0001
\end{tabular}

Maturity stage ${ }^{z}$

Commercial

Tree ripe

$1.98 \mathrm{a}$

Significance

$2.12 \mathrm{a}$

0.088

Cultivar $\times$ maturity stage $\quad 0.160$

Significance

${ }^{\mathrm{z}}$ Within the comparison of cultivars and within the comparison of maturity stages values labeled with different letters are significantly different $(P \leq$ 0.05 , Tukey's honestly significant difference).

TEAC $=$ Trolox equivalent antioxidant capacity; $\mathrm{FW}=$ fresh weight

an acceptance of $64 \%$. For these four tested cultivars, the percentage of consumers disliking them ranged from $13.5 \%$ ('Kadota') to $27.5 \%$ ('Calimyrna'). There was a small percentage of consumers ( $5 \%$ to $11 \%$ ) that chose the neither like nor dislike option.

Tree ripe figs had a higher acceptance than figs harvested at commercial maturity. The average degree of liking for all tree ripe figs was "moderately," whereas the average degree of liking for all commercial mature figs was "neither like nor dislike." The average consumer acceptance for all tree ripe fig cultivars tested reached $86 \%$, whereas all commercial mature fig cultivars tested had only $66 \%$ acceptance. The percentage of consumers disliking the figs was almost three times higher (33\%) for commercial mature figs in contrast to only $9.8 \%$ for tree ripe figs. Fresh fig consumer acceptance was as high as that reported for sweet cherries (Crisosto et al., 2003), table grapes (Crisosto and Crisosto, 2002), tree fruit (Crisosto and Crisosto, 2005), blueberries (Bremer et al., 2008), and kiwifruit (Crisosto and Crisosto, 2001) using the same "in-store" sensory technique

There was a significant positive correlation between SSC and degree of liking (adjusted $\left.R^{2}=0.77 ; P=0.000\right)$ and between SSC:TA ratio and degree of liking (adjusted $R^{2}=0.46$; $P=0.022$ ). This coefficient of determination indicates that only $77 \%$ of the changes in degree of liking are related to changes in SSC. This suggests that other factors related to cultivar flavor perception by consumers are also important in consumer acceptance. Because these quality attributes do not appear to fully explain the cultivar-maturity stage differences in consumer acceptance, further detailed sensory and biochemistry work should be pursued to understand this relationship. For example, the level of latex decreases as fresh figs ripen; thus, this may be an important and unique component of sensory attributes that contribute to the differences in acceptance between these two maturity stages.

Significant but negative correlations were determined between TA (adjusted $R^{2}=0.27$; 
Table 3. Consumer acceptance of four fresh fig cultivars harvested at commercial and tree ripe maturity stages from a commercial orchard in Madera County, CA, 2006.

\begin{tabular}{lcccr}
\hline & $\begin{array}{c}\text { Degree of } \\
\text { liking }(1-9)^{z}\end{array}$ & $\begin{array}{c}\text { Acceptance } \\
(\%)\end{array}$ & $\begin{array}{c}\text { Neither like nor } \\
\text { dislike (\%) }\end{array}$ & $\begin{array}{c}\text { Dislike } \\
(\%)\end{array}$ \\
\hline Cultivar $^{y}$ & $6.3 \mathrm{~b}$ & 72.0 & 8.5 & 19.5 \\
$\quad$ Mission & $5.7 \mathrm{a}$ & 63.5 & 11.0 & 25.5 \\
$\quad$ Brown Turkey & $5.9 \mathrm{a}$ & 63.5 & 9.0 & 27.5 \\
$\quad$ Calimyrna & $6.8 \mathrm{~b}$ & 81.5 & 5.0 & 13.5 \\
$\quad$ Kadota & 0.0001 & & & \\
Significance & & & & \\
Maturity stage & & & & \\
$\quad$ Commercial & $5.3 \mathrm{a}$ & 65.8 & & \\
$\quad$ Tree ripe & $7.0 \mathrm{~b}$ & 85.5 & & \\
Significance & 0.0001 & & & \\
Cultivars $\times$ maturity stage interaction & 0.190 & & & \\
\hline
\end{tabular}

${ }^{\mathrm{z}}$ Degree of liking: 1 = dislike extremely, $2=$ dislike very much, $3=$ dislike moderately, $4=$ dislike slightly, $5=$ neither like nor dislike, $6=$ like slightly, $7=$ like moderately, $8=$ like very much, $9=$ like extremely. ${ }^{y}$ Within the comparison of cultivars and within the comparison of maturity stages, values labeled with different letters are significantly different ( $P \leq 0.05$, Tukey's honestly significant difference).

$P=0.0001$ ) or firmness (adjusted $R^{2}=0.37$; $P=0.0001)$ and degree of liking. These levels of relationships have also been reported in other commodities such as peach, nectarine, and plum (Crisosto et al., 2006). The low impact of TA $(27 \%)$ on consumer acceptance can be explained by the low TA values and variability between these cultivars $(0.22 \%$ to $0.65 \%$ ). In our previous work, TA had a significant impact on consumer acceptance of plums and kiwifruit only when TA values were higher than $0.90 \%$ on ripe fruit (Crisosto and Crisosto, 2001; Crisosto et al., 2004).

\section{Conclusions}

This work demonstrated that fresh fig cultivars currently grown in California have a high level of antioxidants and are highly accepted by consumers. Cultivar and maturity stage had a significant effect on consumer acceptance, but did not affect antioxidant capacity. Degree of liking by consumers and percentage of consumer acceptance were better related to SSC alone than to TA or SSC:TA. Because a large number of consumers are still unfamiliar with fresh figs, educational promotion should be pursued as a result of the large potential for the fresh fig market.

This work also demonstrated the need for cultivars better suited for fresh consumption that have better taste at the less mature stage and/or remain firm enough at the tree ripe stage to tolerate postharvest handling during harvesting and marketing. Different methods of packing and marketing this highly perishable fruit should also be investigated.

\section{Literature Cited}

Aksoy, U. 1998. Why figs? An old taste and new perspective. Proc. First Intl. Symp. Fig. ISHS Acta Hort. 480:25-26.

Aksoy, U., H.Z. Can, A. Misirli, S. Kara, G. Seferoglu, and N. Sahin. 2003. Fig (Ficus carica L.) selection study for fresh market in western Turkey. Acta Hort. 605:197-203.

Battino, M. and B. Mezzetti. 2006. Update on fruit antioxidant capacity: A key tool for Mediterranean diet. Public Health Nutr. 9:1099-1103.

Brand-Williams, W., M.E. Cuvelier, and C. Berset. 1995. Use of a free radical method to evaluate antioxidant activity. Lebensmittel-Wissenschaft + Technologie 28:25-30.
Bremer, V. 2008. Use of preharvest ethephon applications to reduce breba crop load and postharvest performance evaluations of fresh fig (Ficus carica) varieties/selections. MS thesis, Calif. State Univ., Fresno, CA.

Bremer, V., G. Crisosto, R. Molinar, M. Jimenez, S. Dollahite, and C.H. Crisosto. 2008. San Joaquin Valley blueberries evaluated for quality attributes. Calif. Agr. 62:91-96.

Chessa, I. 1997. Fig, p. 245-268. In: Mitra, S. (ed.). Postharvest physiology and storage of tropical and subtropical fruits. CAB International, Wallingford, UK.

Crisosto, C.H. and G.M. Crisosto. 2001. Understanding consumer acceptance of early harvested 'Hayward' kiwifruit. Postharvest Biol. Technol. 22:205-213.

Crisosto, C.H. and G.M. Crisosto. 2002. Understanding American and Chinese consumer acceptance of 'Redglobe' table grapes. Postharvest Biol. Technol. 24:155-162.

Crisosto, C.H. and G.M. Crisosto. 2005. Relationship between ripe soluble solids concentration (RSSC) and consumer acceptance of high and low acid melting flesh peach and nectarine [Prunus persica (L.) Batsch] cultivars. Postharvest Biol. Technol. 38:239-246.

Crisosto, C.H., G.M. Crisosto, G. Echeverria, and J. Puy. 2006. Segregation of peach and nectarine [Prunus persica (L.) Bastch] cultivars according to their organoleptic characteristics. Postharvest Biol. Technol. 39:10-18.

Crisosto, C.H., G.M. Crisosto, and P. Metheney 2003. Consumer acceptance of 'Brooks' and 'Bing' cherries is mainly dependent on fruit SSC and visual skin color. Postharvest Biol. Technol. 28:159-167.

Crisosto, C.H., D. Garner, G.M. Crisosto, and E. Bowerman. 2004. Increasing 'Blackamber' plum (Prunus salicina Lindell) consumer acceptance. Postharvest Biol. Technol. 34:237244.

Ferreyra, R.M., S.Z. Viña, A. Mugridge, and A.R. Chaves. 2007. Growth and ripening season effects on antioxidant capacity of strawberry cultivar Selva. Sci. Hort. 112:27-32.

Food and Agriculture Organization. 2007. Data archives. FAOSTAT. 24 Nov. 2007. <http://faostat. fao.org/site/408/DesktopDefault.aspx $>$.

Hertog, M.G., P.M. Sweetnam, A.M. Fehily, P.C. Elwood, and D. Kromhout. 1997. Antioxidant flavonols and ischemic heart disease in a Welsh population of men: The Caerphilly Study. Amer. J. Clin. Nutr. 65:1489-1494

Ilgin, M. and A.B. Küden. 1997. Table fig selection study in the Kahramanmaras Province of Turkey. Acta Hort. 441:351-358.
Kader, A. 2001. Importance of fruits, nuts, and vegetables in human nutrition and health. Perishables Handling Qrtly. 106:4-6.

Küden, A.B., S. Bayazit, and S. Çömlekcioglu. 2008. Morphological and pomological characteristics of fig genotypes selected from Mediterranean and South East Anatolia regions. Acta Hort. 798:95-102.

Lawless, H.T. and H. Heymann. 1998. Acceptance and preference testing, p. 430-479. In: Lawless, H.T. and H. Heymann (eds.). Sensory evaluation of food, principles and practices. Chapman and Hall, New York, NY.

Michailides, T.J. 2003. Diseases of fig, p. 253-273. In: Ploetz, R.C. (ed.). Diseases of tropical fruit crops. CABI, Wallingford, UK

Obenauf, G., M. Gerdts, G. Leavitt, and J. Crane. 1978. Commercial dried fig production in California. Division of Agricultural Sciences, University of California.

Piga, A., A. Del Caro, G. Milella, I. Pinna, V. Vacca, and S. Schirru. 2008. HPLC analysis of polyphenols in peel and pulp of fresh figs. Acta Hort. 798:301-306.

Scalzo, J., A. Politi, N. Pellegrini, B. Mezzetti, and M. Battino. 2005. Plant genotype affects total antioxidant capacity and phenolic contents in fruit. Nutrition 21:207-213.

Shukitt-Hale, B., A.N. Carey, D. Jenkins, B.M Rabin, and J.A. Joseph. 2007. Beneficial effects of fruit extracts on neuronal function and behavior in a rodent model of accelerated aging. Neurobiol. Aging 28:1187-1194.

Soby, S. 1997. Fig fact sheet. Fruit \& Nut Research and Information Center. 8 Nov. 2007. <http:// fruitsandnuts.ucdavis.edu/index.html $>$.

Solomon, A., S. Golubowicz, Z. Yablowicz, S. Grossman, M. Bergma, H.E. Gottlieb, A. Altman, Z. Kerem, and M.A. Flaishman. 2006. Antioxidant activities and anthocyanin content of fresh fruits of common fig (Ficus carica L.). J. Agr. Food Chem. 54:7717-7723.

SPSS_16.0. 2008. SPSS Base 16.0 for Windows. SPSS Inc., Chicago, IL.

Stover, E., M. Aradhya, C. Crisosto, and L. Ferguson. 2007a. Overview of the California fig industry and new interest in varieties for fresh fruit. Proc. California Plant and Soil Conference: Opportunities for California Agriculture, Sacramento, Calif. p. 169-175.

Stover, E., M. Aradhya, L. Ferguson, and C. Crisosto. 2007b. The fig: Overview of an ancient fruit. HortScience 42:1083-1087.

Synovate. 2004. Fig exploratory attitude and usage study. Presentation of results. Research reinvented. Prepared for Kraft Foods. Job number P979 (Release \#20047430)

Tous, J. and L. Ferguson. 1996. Mediterranean fruits. Purdue University. NewCROP. 20 Oct. 2007. <http://www.hort.purdue.edu/newcrop/ default.html $>$.

U.S. Department of Agriculture. 2007. Noncitrus fruits and nuts 2006 summary. Agricultural statistics board. NASS, USDA. 29 Nov. 2007. $<$ http://usda.mannlib.cornell.edu/MannUsda/ viewDocumentInfo.do?documentID=1113>.

Vinson, J.A., L. Zubik, P. Bose, N. Samman, and J. Proch. 2005. Dried fruits: Excellent in vitro and in vivo antioxidants. J. Amer. Coll. Nutr. 24:44-50.

Vizzotto, M., J. Cisneros-Zevallos, D.H. Byrne, D.W. Ramming, and W.R. Okie. 2007. Large variation found in the phytochemical and antioxidant activity of peach and plum germplasm. J. Amer. Soc. Hort. Sci. 132:334-340.

Wang, S.Y., C.-T. Chen, W. Sciarappa, C.Y. Wang, and M.J. Camp. 2008. Genetic improvement of fruits and vegetables. J. Agr. Food Chem. 56:5788-5794. 